\title{
Attenuated Sovereignty: An Immodest Proposal for Addressing Ethnic Diversity
}

\author{
Chris Woltermann
}

Published online: 20 January 2011

(C) Springer Science+Business Media, LLC 2011

\begin{abstract}
The conventional sovereignty that has prevailed for the past several centuries restricts the options open to ethnic minorities in multiethnic populations that are subject to a single sovereign authority. Minorities will either trend toward integration with majority populations or else the direction of change will be toward separation and the establishment of new, smaller sovereign states. There are serious problems with both options. The present proposal is for a form of diluted or "attenuated" sovereignty whereby, in its most basic form, a particular ethnic minority would be afforded limited sovereignty in a specified area within an existing sovereign state's overall territory. An attenuatedsovereignty government established in the specified area would be answerable to - and have authority over-only those persons of the designated ethnic minority who have opted to affiliate themselves with it. Distinctive to this proposal, all other persons, irrespective of their ethnicity, could remain in the delimited area and remain subject to the pre-existing, conventionally sovereign authority. This proposal includes various strategies to make attenuated sovereignty a practical, workable option. The notion of attenuated sovereignty is not as fantastical as it may seem at first glance. Re this assertion, the conventionally sovereign state is everywhere at bay. Its best days are behind it. Under the circumstances, in some situations, attenuated sovereignty could prove advantageous to both ethnic minorities and majority populations willing to accommodate them in the creative manner here proposed.
\end{abstract}

Keywords Sovereignty $\cdot$ Ethnic diversity $\cdot$ Multiethnic populations $\cdot$ Ethnic conflict

\footnotetext{
C. Woltermann $(\bowtie)$

215 W. Butler St.

Fort Recovery, OH 45846, USA

e-mail: cwolter49@yahoo.com
}

Sovereignty is the sticking point. Its two essential elements, of who makes government's peremptory decisions and where those decisions have their binding effect, must inform any meaningful strategy to ease inter-ethnic tensions. Disaffected ethnic minorities can be accommodated in a manner not detrimental to majority populations. The key to doing so lies in radical adjustments to the practices and legal understandings long associated with the notion of sovereignty. Let anyone who doubts this proposition consider how the operational details of territorial control, i.e., the governance of people on the land where they live, constrain the dynamics of inter-ethnic relations. Only two possibilities suggest themselves. For any minority people anxious over their situation, either there will be movement toward some form of integration with the larger population of an existing sovereign state, or else the direction of change will be toward separation and the formation of a new sovereign state within boundaries of its own. Both alternatives are troubling for minority persons who have neither reconciled to their numerical weakness nor overcome an unbidden preoccupation with imagining themselves in happier circumstances.

An insufficiently discussed aspect of ethnicity looms large in multiethnic societies. Every ethnic group, regardless of whether it is a majority or a minority, exhibits differences among persons who yet claim the same social identity. Such people are never so similar that they fail to vary in their emotions, thoughts, and behaviors. Especially consequential intra-ethnic differences come to the fore during interactions with persons of alien ethnicity. People perceive and deal with persons outside their own group in diverse ways which not infrequently, e.g., when the safety of group members is at stake, are intra-ethnically antagonistic. In-group differences, no less than ethnic variety, characterize multiethnic social reality. Their influence is pervasive in the experiences of disaffected minority persons who find the sovereignty-grounded alternatives of integration and separation to be problematic. 


\section{Separation and Integration}

Separation should be understood as the establishment of sovereignty over persons and territory formerly subject to a pre-existing sovereign state. Examples include: the Norwegian secession from Sweden in 1905, the Slovaks and the Czechs separating from each other in 1992, and the Eritreans throwing off Ethiopian domination in 1993. Despite these and other instances, ethnically based separation rarely comes to fruition. Even with the advantage of the foremost facilitating condition, viz., the geographical concentration of a minority population where it is or comes close to being a regional majority, separatists seldom succeed. Examples of seemingly achievable but failed separation are illustrative: Quebecois in Canada, Flemish and Walloons in Belgium, Tamils in Sri Lanka, Russians in Ukraine's Crimea, Chechnyens in Russia, Ibos in Nigeria, Uighurs in China, Basques in Spain, and Muslim Kashmiris in India. In each of these cases, disunity in minority ranks, occasioned by dissenters opposed to separation, has proven decisive on the side of a central government bent on maintaining its sovereignty. Too much importance is attributed to the violence sometimes employed by central governments to suppress separatists. Such violence always requires the participation of collaborators against their own people. The brutality of the resultant intra-ethnic strife is often horrific, as the recent history of Chechnya attests.

Agitation to promote ethnic separation typically does not draw enough willing supporters. The effort becomes a fool's errand wherever a minority, e.g., Turcomans in Iraq or Afrikaners in South Africa, is widely dispersed and in no place near to constituting a regional majority. Even then, zealots cling to separatist fantasies and seek to realize them through such gestures as theatrical posturing, vacuous sloganeering, and the proselytizing of misfits vulnerable to chicanery. In effect, a commitment to ethnic separation equates to accepting the status quo with its inter-ethnic tensions intact. Delusional separatists represent a waste of human energy and a reservoir of bitterness which, given the right catalyst, can result in disruptive behavior up to and including terrorism. The usual futility of the separatist project leaves ethnic minorities with integration as their default option.

Integration has problems beginning at the conceptual level. Unlike separation, for which a single and narrow meaning works well, integration can be construed in multiple ways, all of which are relevant to the present discussion. One understanding of integration ignores ethnic diversity and treats any sovereign state's population as integral, and in that sense integrated, provided only that sovereignty has not lapsed in the course of civil war, foreign invasion, or some other calamity. Although the oneness of a multiethnic population unified by reference to sovereign authority is tautological, it becomes a topic of discourse in times of crisis. Politicians and journalists then berate the populace with harangues whose gist is "we must put aside our differences and work together." Within a context of inter-ethnic tensions, this assertion of a need for unity generally receives a polite hearing but otherwise has little impact on countervailing tendencies. Like the separatist project, that of integration inspired by sovereignty effectively endorses the status quo.

Another version of integration describes the condition of an erstwhile multiethnic population in which assimilation has either eliminated ethnic differences or diminished them to the point of insignificance. As the outgrowth of a comprehensive process involving exogamy, such ethnic homogeneity develops slowly, never in less than many generations, and does so principally at the person-to-person level through incremental, largely undeliberated changes in individuals' behaviors. The gradualism and the unplanned character of assimilationinduced integration make it an awkward standard for strategies to ease contemporary inter-ethnic tensions. Hardly anyone sincerely advocates it. Although it often figures in politically correct pontifications, its routine conflation with "multiculturalism," "diversity," and "pluralism" betrays that a quite different variety of integration is envisioned.

The third and final type of integration refers to intergroup harmony, understood not as the absence of tensions, though that is not altogether out of the question, but rather their lessening pursuant to inter-ethnically reconciliatory measures imposed by sovereign authority and backed by the force of law. Integration in this sense is a governmental undertaking led by politicians with a pragmatic aversion to the more thoroughly transformative, far less feasible projects of separation and integration in its second form. To be clear, meliorist integrationists are social engineers. Whether they grudgingly accept their sovereign state's multiethnic status or, as is now the fashion, they enthusiastically embrace it under the rubric of multiculturalism, they enlist the state's legislative and police powers to compel and habituate people to get along with one another tolerably well across ethnic divides. A tentative, even experimental approach characterizes this social engineering. If one expedient doesn't work, or doesn't work well enough, it can be adjusted, supplemented, or replaced with a new initiative. The entire process favors the growth of government's reach and intensity, an emblematically modern development resulting from multiple causes.

Politicians seeking the integration of interethnic harmony resort to a wide array of legislated measures. Of these, perhaps the most familiar come under the heading of "affirmative action." They comprise any and all programs meant to redistribute wealth inter-ethnically and to increase opportunities for members of groups deemed to be disadvantaged. Depending on circumstances, the targeted beneficiaries may form a majority, as is now the case in both Malaysia and Namibia, but usually those to be conciliated are in the minority. Social engineering directed 
toward integration finds additional scope in education and the sovereign state's civic symbols. With respect to education, teachers are enjoined to present a rewritten history that stresses the "contributions" of the ancestors of the contemporary disadvantaged. Civic symbols are manipulated in an analogous manner, e.g., by the establishment of holidays honoring historical figures associated with particular ethnic groups and by the erection of new, ethnically oriented public monuments.

Criminal law likewise gets changed to foster integration. Examples include "hate crime" laws in the United States and ordinances criminalizing "insensitive" speech in various African and European countries. Measures with an overtly political focus appeal strongly to integrationists. Here there is great variety, including ethnic autonomous regions in China and Russia, the proposed institutionalization of Islamic law in Pakistan's Swat Valley, modern Poland's constitutional provision reserving two seats in the lower house of its legislature for ethnic German parties, and the American practice of "gerrymandering" electoral districts to favor designated minorities. Some pro-integration efforts, e.g., Israel's exemption of Arab citizens from military conscription and newly enacted programs in Australia to restrict aboriginal access to alcohol, are difficult to classify as economic, political, or whatever. However categorized, all measures legislated by a sovereign state to nurture inter-ethnic harmony form a sort of web, not without internal contradictions, of social engineering meant to control how people feel, think, and act.

Never do attempts to integrate through sovereign action neatly fulfill the expectations set for them. Less reliably effective than diffusely effect-producing, they have repercussions that include some at odds with others, while some evidence a more profound social transformation than acknowledged in advance. Unintended consequences, as in the "law of unintended consequences," occur routinely. Contingency beclouds even the outlook, almost always assumed to be favorable, for assimilative integration to develop as a fortuitous byproduct of governmental initiatives. For example, does affirmative action for non-Hindu tribal peoples in Bihar and Orissa increase the likelihood that they will assimilate with the broader Indian population, or does it permanently stigmatize them - perhaps with their connivance to secure continuing preferential treatmentand thus render assimilation less probable? This question can be recast countless times using different examples, but its answer in every case must remain in abeyance pending long-term historical change. More pertinent is the question of whether the historical understanding of sovereignty must exert a stranglehold on change. If so, the most likely prospect over the next several generations, and perhaps even the next several centuries, is for a condition of ongoing inter-ethnic tensions punctuated by sovereign improvisations to mitigate them. This scenario is plausible because a build-up of governmental and ethnic vested interests works in its favor. Another possibility, though, involves revising sovereignty itself. Some such revision makes sense when considered in light of the convoluted responses from within minority communities to integrative social engineering.

Intra-ethnic differences take on critical importance in this context. The focus should be not on discrete in-group factions nor on individuals unrealistically thought to be self-consistent, but rather on fluid patterns of response to government's integrative project. These blur into one another so that, in the experience of an ethnic minority person, they can co-exist ambiguously and dynamically, with one pattern in transitory ascendancy while also in a condition of some discord with the others. At least three patterns can be discerned.

The first of these treats social engineering as a distraction from the concerns of everyday living. For persons manifesting this response, an integrative measure can be welcome, mildly annoying, or both. In any case, people seek to render the measure emotionally peripheral, to incorporate it into their daily routines where it will be less irksome and no less useful for making few demands on their attention. They wish to concentrate on more immediate concerns. Mundane and apolitical, this response occurs ubiquitously. It is, taken by itself, compatible with movement toward assimilative integration.

Undisguised enthusiasm for integrative measures marks the second pattern of responding to them. Its exemplars are politicized individuals who experience a sense of grievance as essential to their ethnic identity. They make sovereign authority's solicitude central to their lives and selfconsciously avail themselves of government-provided opportunities. As entailed by their self-consciousness, their conduct has an aspect of nervous disengagement, of willful role-playing that they fear exposing, even while being engaged. A person manifesting this response feels both a strong sense of self and the need to fashion oneself into a cooperative participant, one who satisfies conditions and meets expectations, in government's integrative designs. Such a person looks for his cooperation to realize benefits in his everyday life, although unlike a respondent typical of the first pattern, he wants to remain heedful of their origin. This pattern of response reinforces itself with demands for additional integrative measures. Its influences on any tendencies toward assimilative integration are negative.

The third pattern of response to integrative social engineering is characterized by disaffection in its precise lexigraphic sense, following Webster's unabridged second edition, of "the absence or alienation of affection, attachment or good will; discontent or disloyalty, especially toward the government" (emphasis added). Disaffected 
minority persons despise the government that attempts to integrate them. They resent its sovereign authority which they encounter as the power of persons not like themselves to make the ultimate decisions that determine how they must live on the land where they do live. They feel as if their lives were not their own, as if they could be their changing selves only if hidden behind closed doors in their homes or, for the wealthy among them, secluded within their walled estates. If they were able to live as they prefer, they would lead their lives openly, i.e., expansively in both geographic and public space, and not under the disruptive gaze - be it solicitous, critical, curious, or whatever - of ethnically different people who are in concert with sovereign authority.

Disaffected minority people can express contempt for "their" government in various ways. By veering off into either separatist activities or the first pattern of response to government-sponsored integration, they generally pose little threat to the status quo. They may instead or also, however, agitate for an open-ended expansion of preferential treatment, which legislatures and bureaucrats are prone to afford in the name of "integration," but which would in fact reward a cynical effort to extract maximum benefits while mocking the government, overburdening it, and fomenting its dysfunction. This style of coping with integration features prominently in Muslim immigrant communities in Europe, but it occurs wherever integrative social engineering attempts to master inter-ethnic tensions. Disaffection anywhere has the potential to eventuate in violence, typically with the responsible militants having neither a standard of success beyond the immediate efficacy of any particular violent act nor any but a vague notion of a new social order that might follow their triumph. Rooted in contempt for existing sovereign authority, the third pattern of response is inimical to assimilative integration.

There would be no reason to think about transcending the established practices of sovereignty if only the first pattern of response to integrative social engineering always or usually prevailed over the other patterns. To the bewilderment of the more sentimental social scientists, people do not behave so compliantly. The politicians who promote the integrative project have a somewhat better grasp of reality. Ethnic diversity and inter-ethnic tensions, they realize, are facts of life. Modern governments arguably cannot and, at any rate, do not let people muddle through these tensions on their own. Herein lies the genesis of integration under the aegis of government. Starting sometime around World War II, every aspect of life grew intensely politicized to the degree that now, in the twentyfirst century, there remains virtually nothing for which government is not responsible or for which it can escape blame if anything "goes wrong." The least excusable political misdeed is inaction; the most praiseworthy fidelity is to be seen "doing something," even when the consequences prove objectionable and elicit calls-not for sovereign forbearance - but for government, again, to "do something."

Pervasive politicization explains why the second pattern of response to governmentally driven integration is the most influential, even if, as is often the case, it dominates the behavior of less than a plurality of a targeted ethnic group. History is made by resolute minorities, including sub-minorities within ethnic minority populations. Perhaps not needless to say, it makes no difference and is indeterminable whether the impetus for integrative activism comes from an assertive faction (or factions) within an ethnic minority or from politicians "on the make." The relationship is symbiotic so that, as noted earlier, there develops a build-up of governmental and ethnic minority vested interests conducive to ongoing inter-ethnic tensions. This development is self-exacerbating, not least because the second response to integrative social engineering involves demands for additional integrative measures. Of course, ambitious politicians answer and/or evoke these demands.

The greatest social gamble of our era is that clever politicians can repeatedly devise ways to manage ethnic diversity and thereby keep inter-ethnic tensions under control. This requires piling integrative measures upon integrative measures to alleviate the chronic tensions left unresolved and often stimulated by prior instances of social engineering. Such management of ethnic diversity bears a close resemblance to modern government's economic role. In both cases, government works through crisis after crisis, usually with relatively long quiescent periods in between. Optimists have faith that their political leaders will prove more adept as social engineers than as economic managers. Crises involving inter-ethnic relations, the optimists assume, are more foreseeable and tractable to early governmental intervention than are economic dilemmas.

Time and time again, however, superficial appearances of inter-ethnic calm have obscured sublimated tensions only to collapse abruptly in paroxysms of hatred and violence. In retrospect, the tensions are widely appreciated to have been almost palpable, though largely inaccessible to contemporaneous description and discussion. A common occurrence in historical colonial societies, the sudden eruption of interethnic hatred and violence out of a seemingly placid milieu continues to threaten multiethnic societies because of the third pattern of reponse to governmentally driven integration. The optimism on behalf of skillful social engineering is misplaced. To make matters worse, the third pattern of response - of contempt for existing sovereign authority and those in league with it - is on the rise due to, among other factors, the assertiveness of politicians whose multiculturalist stance renders them still more contemptible. 
Modern men and women have committed their futures to the bet that government, in the form of politicians and bureaucrats who embody its sovereignty, can control interethnic tensions. Having been placed, this bet cannot be rescinded. It can, however, be hedged, and the way to do so is by instituting a system attenuated sovereignty.

\section{Attenuated Sovereignty}

The essential features of this recommendation for attenuated sovereignty come together in the proposition that persons who share a particular minority ethnicity, but only the willing among them, should be affiliated with an ethnically based government having quasi-sovereign jurisdiction only over themselves and only inside a generously extensive territory delimited for their benefit, but not reserved exclusively for them, within the boundaries of an existing sovereign state. Attenuated sovereignty clearly has some unconventional elements. Although these may seem utterly novel, they correspond to medieval practices, in both Western Europe and the Byzantine Empire, according to which persons of differing ethnicity could have different rights exercisable upon a given parcel of land ranging from a small field to a vast province. This medieval approach held sway before anyone began to think in terms of sovereignty and sovereign states. With adjustments to the early-modern invention of sovereignty, it is an approach that can be revived by reconciling the ancient principle of ethnic solidarity with the modern one of individual choice. The devil, as the adage goes, lies in the details, all of which require explication.

Only the willing among an ethnic minority population can be expected to answer to an ethnically based government exerting attenuated sovereignty. No other course is practical because of the persistence of intra-ethnic differences. Individuals of the same ethnicity experience its allure at variable intensity. Provided only that some unquantifiable "enough," whether more or less than half, of a minority people wish to have their own government, attenuated sovereignty is feasible. By not mandating either an absolute majority or a set smaller percentage of a minority population as a prerequisite for systemic change, an existing sovereign government amenable to attenuated sovereignty can avoid tendentious, sterile questions about "what these people really want." There are no "these people," only persons of a not uniformly shared ethnicity. If a significant number of them, however that is adjudged, is deemed favorable, however that is determined, then attenuated sovereignty can be established.

Attenuated sovereignty requires a territorial base, a place within whose boundaries a government exercising such sovereignty can govern a resident population. Every instance of conventional sovereignty likewise involves this capacity, but the two sovereignties differ in terms of how much of a territory's total population falls under their respective kinds of governance. Whereas conventional sovereignty covers an entire population, attenuated sovereignty extends only to consenting persons among the ethnic minority for which a specific expanse of ground is made available. Explicitly excluded from the reach of attenuated sovereignty are its territory's residents who are either of differing ethnicity or of the same ethnicity but unwilling to associate themselves with its ethnically rooted government. All such persons would remain answerable to the conventionally sovereign authority of a larger and pre-existing state of which only some portion of its total area the attenuatedsovereignty territory occupies. To be accurate, the conventional sovereignty of a state that allows attenuated sovereignty foregoes some of its conventionality - and thereby itself becomes "attenuated" or diluted-within the territory delimited for an ethnic minority. There full conventional sovereignty confines itself to persons unaffiliated with the attenuated-sovereignty government and, vis-á-vis that government's clients, restricts itself to powers not devolved upon them and their regime.

Neither the inception nor the continuation of an attenuated-sovereignty government need result in largescale migrations of persons across the boundaries of the territory demarcated for it. At the outset, the only necessary such movement of population would be of those persons of the designated ethnic minority who both have been residing outside the new territory's boundaries and have chosen to come under the jurisdiction of their own ethnically based government. They would have to establish and maintain residence in the new territory. No one else would have to relocate, although members of the ethnic minority already living in the territory would be required to opt explicitly for affiliation with the attenuated-sovereignty government if they did not want to remain under the full jurisdiction of their conventionally sovereign authority. Once established, attenuated sovereignty would impose the same requirements on those ethnic-minority persons, current nonresidents and residents alike, wanting to associate themselves with it. Persons already subject to the attenuatedsovereignty government but wanting to sever this connection would be obliged, for reasons soon to be made clear, to relocate outside the territory under that government's jurisdiction.

The key to making attenuated sovereignty workable lies in the character of the decisions whereby individuals commit themselves to it. Here the point should be repeated and stressed that attenuated sovereignty offers the prospect of reconciling ethnic solidarity with individual choice. A choice is no less "individual" when it is for the chooser's potential to experience ethnic solidarity together with like- 
minded others in a way mediated by a government uniquely their own.

Individual choice comes to a head in individual decision. For a decision to opt in favor of attenuated sovereignty to be meaningful, it must satisfy pair of superficially contradictory requirements. First, it must create a binding commitment; second, this commitment cannot be so binding that it is inescapable. The first requirement calls for only brief comment. Without some way to assure a binding commitment, persons who have opted for attenuated sovereignty would be able to "game the system" by opportunistically switching their allegiance back and forth between their ethnically rooted government and the conventionally sovereign government having full jurisdiction over some of their co-residents. Individuals should be strongly deterred from transferring their clientage from one government to another because of, e.g., a desire for lower taxes or an effort to receive more generous social services. An attenuated-sovereignty government having such a tenuous relation with its subjects could not survive.

An utterly unbreakable bond between an individual and his attenuated-sovereignty government would likewise subvert the system. This can be inferred by analogy with conditions in contemporary Malaysia where Muslims, virtually all of whom are the ethnic Malays who constitute a majority of the country's population, are prohibited from consuming alcohol. Malaysia's law in this respect operates differently from the same prohibition in Saudi Arabia where almost everyone is Muslim. The Malaysian population includes large ethnic Chinese and Indian communities whose overwhelmingly non-Muslim members are not enjoined from alcohol consumption. Under the circumstances, young and Westernized Muslims sometimes join their non-Muslim compatriots for drinks in public. Two persons of the same age but differing religions (and, in effect, differing ethnicities) can share a pitcher of beer while one acts legally and the other breaks the law. Such Malaysian scofflaws put the country's police and courts in an untenable position which, as of this writing, has not been resolved.

The Malaysian example provides two valuable lessons, viz., first, that ethnically based differing legal codes operating in the same region are problematic and, second, that the political "where," the on-this-expanse-of-ground locus of social life, cannot be expunged from political considerations. Malaysia's example also suggests how the second lesson can help resolve the problems of the first. The missing link is the limited territorial scope of attenuated sovereignty. If Malaysia' $s$ laws were to be changed so that in some delimited here Muslims had no legal recourse to alcohol, whereas in the remaining there they endured no such restriction, the tension between religious/ethnic solidarity and individual choice would be markedly reduced. Perhaps not needless to say, such reform would require that both the no-alcohol-for-Muslims here and the Muslims-may-drink-as-they-please there be extensive territories so that the practices of legally enforced abstinence and lawful imbibing would be less likely to make overt mockeries of each other.

Attenuated sovereignty as here proposed calls for a binding commitment that, informed by the Malaysian example, is not irremediably binding. The compromise is achieved through a residency rule. If someone subject to an attenuated-sovereignty government wishes to free himself of what he perceives to be its unacceptable strictures, he must migrate to that portion of his country's territory where unrivaled conventional sovereignty reigns.

Provisions must be made for married persons either already within the population subject to an attenuatedsovereignty government or seeking to become part of that population. Various ways to address this issue are conceivable, and the viability of attenuated sovereignty does not depend on which is selected. The simplest and arguably best policy would be a household rule according to which husband and wife would have to agree on any change of status, with their dependent children, up to some age specified by law, automatically following suit. Upon reaching the age set for legal majority, a young adult would have to opt one way or the other. This could be handled in any of several ways.

Decisions to affiliate oneself with and to remain subject to an attenuated-sovereignty government need not entail any rights of electoral participation. At the theoretical level which is the focus of the present discussion, the question of electoral rights is open and contingent upon constitutional determinations to be made if and when theory becomes practice. Interested parties willing to consider attenuated sovereignty will probably assume an electoral constitutional order, of the sort nowadays styled democratic, affording a universal adult franchise to the governed population. However, there is no a priori reason why the franchise could not be restricted by reference to, e.g., gender, marital status, literacy, educational attainment, wealth, religion, etc. A broadly acceptable constitutional order could even, in unusual circumstances, dispense with elections altogether, as in a syndicalist system or one of clerical rule. The viability of attenuated sovereignty is less a matter of its process of governance than a question of the division of powers between attenuated and conventional sovereignties.

Certain governing prerogatives would necessarily remain with the conventionally sovereign authority. These include powers needed for the country's military defense and conduct of foreign affairs. Such powers could not be meaningfully devolved upon an attenuated-sovereignty government. With somewhat lees rigor, the same can be said of powers relating to infrastructure-roads, railways, 
utilities, harbors, etc.-as well as to public health and environmental protection. These are areas of governmental activity for which the conventionally sovereign establishment would retain either full responsibility or, possibly, merely primary responsibility, with an attenuatedsovereignty government serving as its junior partner. A more balanced sort of shared responsibility would be feasible in civil and criminal law and routine policing, although there is no reason why the attenuated-sovereignty authorities could not be completely autonomous in these matters whenever the only persons involved are their own people.

Complete or nearly complete autonomy for the attenuated-sovereignty government could and should be the rule in both education and the broad field of social welfare. Taken together, these public concerns are probably the most clamorous for politicians' attention and certainly, at least in countries with developed economies, the most demanding of governmental expenditures. People are willing to pay dearly for education and the services of the modern welfare state. Therefore, to enjoy the fullness of responsibility in these matters, the attenuated-sovereignty government should be empowered to levy taxes on the population subject to it. Taxes so raised should meet with an elimination of the corresponding taxes imposed by the conventionally sovereign government. In other words, the attenuated-sovereignty government's people should not be obliged to continue paying the conventionally sovereign government to fund activities that it has relinquished.

Any attenuated-sovereignty government would need additional tax-derived revenue to fund its other, probably less costly activities. Prominent among these would be the social-welfare-related matters of affirmative action and job protection. With respect to affirmative action, an attenuated-sovereignty government should be able to institute and fund whatsoever measures as are deemed advantageous to its people. It should not be able to exact any resources for this purpose from the conventionally sovereign government, nor should it make demands on persons fully subject to conventional sovereignty, nor should its people be bound by any affirmative-action provisions or anti-discrimination laws but their own. With respect to job protection for its people, an attenuatedsovereignty government would need to resort to measures other than the currently favored ones of high import tariffs and/or regulatory barriers to imports. An attenuatedsovereignty government would have no authority vis-á-vis foreign trade. However, it could still protect selected jobs through the use of subsidies. This expedient might be foolish, but its costs would be obvious, a claim that cannot be made regarding the indirect costs always inflicted by protective tariffs and regulations.

Any attenuated-sovereignty government's fiscal viability would depend on the size and wealth of the population from which it could draw tax revenue. Reflecting this reality, the extent of the territory allocated to an ethnic minority for their own government should be as generous as possible. A good tentative rule is that the territory should amount to a significantly greater percentage of a country's entire area than the ethnic minority constitutes in the country's total population. Several considerations lie behind this recommendation. For reasons requiring no elaboration, every conventionally sovereign government would be reluctant to the point of refusal to include any of its major urbanized regions in an attenuated-sovereignty territory. That territory should therefore have more land, albeit land less supportive of a dense population, to compensate for the denial of crowded urban acreage. Ethnic partisans of attenuated sovereignty would be prudent to welcome such an arrangement because of the deleterious effects of urban living on ethnic distinctiveness. Cities function as social solvents favoring human homogenization. But cities also, and as part of the same process, cause and exacerbate interethnic tensions as some members of this or that ethnic group - here, again, intra-ethnic differences manifest themselves - resist homogenization and assert their parochial ethnic fidelity. Under the circumstances, an attenuatedsovereignty territory can serve as an invaluable social safety valve. That it should work well is in the interests of everyone in a multiethnic population. To this end, a large attenuated-sovereignty territory is advisable.

The foregoing sketch is intended to be suggestive. It covers attenuated sovereignty's definitive elements but leaves ancillary matters in abeyance. Although some of these latter are important, and a division of sovereignty is unimaginable absent their resolution, they admit of such variety in $a d$ hoc solutions that they warrant no more than a brief mention in this general discussion.

There would doubtlessly be occasions when the conventionally sovereign and the attenuated-sovereign governments contest each other's prerogatives. Procedures would have to be established to settle such disputes. Likewise, there would have to be provisions, notably relating to taxation, to handle the probably not infrequent occurrence of some of attenuated sovereignty's adherents residing in their own territory while working outside of it. Still another issue is that of what political rights, if any, those who have opted for attenuated sovereignty would enjoy relative to the conventionally sovereign government. Could they petition its legislature, courts, and bureaucrats? Could they vote in elections held under its auspices? These questions are open to various answers adapted to particular circumstances.

Attenuated sovereignty calls for a postmodern consciousness that rejects equally belief in ethnicity as destiny and the understanding of ethnic background as nothing more than an impediment to self-actualization. Ethnic rootedness and individualism need not deny each other, 
and the two can come together in a grand synthesis accommodating both persuasions. Basic to this scenario is sovereignty's central concern, common to its conventional and attenuated versions alike, of governing people on land where they live. Freedom can be enhanced by providing the indispensable spatial context - attenuated sovereignty's "own" territory-for choice in favor of ethnic solidarity. Even and perhaps especially if thus empowering individuals requires the deliberate and grudging good will of negotiating parties prone to despise one another, attenuated sovereignty is a project worth the effort.

\section{Objections and Rebuttals}

Radical deviations from customary practices make attenuated sovereignty an easy target for objections to treating it as a serious proposal. Although these objections seemingly have unassailable good sense on their side, they rest upon a hidebound conventional wisdom complacently out of touch with both history and the rapidly changing realities of contemporary life. Rebuttals to the objections constitute some of the best imaginable arguments for attenuated sovereignty.

Objection \#1. Instituting attenuated sovereignty to address ethnic diversity is like using a shotgun to rid one's roses of aphids. A far better, much simpler approach is for existing governments to treat people equally by affording each individual the universally valid rights that are his or her birthright. Inter-ethnic tensions would diminish and eventually fade away. Individual rights, not group rights, are the key.

To the contrary, government's focus on the individual stokes group-oriented parochialisms and intergroup tensions. Agitation for the individual's allegedly innate rights arose with the European Enlightenment and unfolded in tandem with numerous nationalisms, each of which demanded the conformity of typically enthusiastic, supposedly "liberated" individuals. This phenomenon persists. Not for nothing do multiculturalist lunacies make their deepest inroads in Western societies where the dogma of individual rights prevails virtually unchallenged. Government's solicitude for the individual fails to weaken and, in fact, stimulates social (not just ethnic) parochialisms because the individual, every individual, is socially contextualized. Even roguish, ostensibly very independent characters have their restrictive social contexts. Although the American cowboy and the Japanese samurai are individually assertive figures in their respective cultures, each would correctly perceive the other to be bound by his culture's peculiar norms.
Persons treated by their government solely as the bearers of individual rights seek refuge in their respective groups. Such persons do not become desensitized to ethnic differences, nor do inter-ethnic tensions abate.

Objection \#2. Reference has been made to nationalism, a topic heretofore omitted from the proposal for attenuated sovereignty. Nationalism clearly belongs in the discussion. Attenuated sovereignty is objectionable because it would encourage nationalism and all the evils inseparable from it.

Nationalism and the evils said to be inseparable from it have no bearing on attenuated sovereignty. Historical and contemporary nationalisms are alike in that nationalists always struggle with dissenters. For a person who ethnically "belongs" in what nationalists style "the nation," refusal to join is not an option. Nationalists' persuasive techniques range from the gentle through the mercilessly brutal. Whatever the means, everyone who meets a sort of national profile is to be brought into "the nation," personal preferences notwithstanding. The contrast with the individual's situation pursuant to attenuated sovereignty could not be sharper. Attenuated sovereignty seeks to accommodate individual choice rather than ride roughshod over it.

Properly understood, attenuated sovereignty is an antidote to nationalism. An ethnic population is not a nation, nor does ethnicity equate to nationality.

Objection \#3. The capital and the human energy necessary to institute an attenuated-sovereignty system could be better deployed to foster economic growth, the true path to reducing inter-ethnic tensions. Prosperity makes people content. A man determined to get rich, and living in a society where that is possible, cares little about his ethnicity. That's also the case when middle-class affluence, rather than riches, is more realistic. A free-enterprise, low-tax environment offers the best chance for overcoming the problems of ethnic diversity.

Only doctrinaire libertarians feel comfortable with this argument. Prosperity certainly is better than poverty, but its effects among minority persons are divergent. True enough, improved material conditions frequently move people to downplay their ethnicity. Perhaps still more often, however, as people find themselves sated with consumer goods and motivated to "get more out of life," they eagerly return to their ethnic roots. A common occurrence is that of the successful man renewing and deepening a long sidelined interest in his family's heritage. Moreover, not just a few 
minority persons in multiethnic societies unobtrusively grow prosperous without ever integrating themselves into a wider population. Some of the most vehemently ethnocentric sentiments to be found anywhere appear among such individuals and their descendants.

Prosperity leaves many minority persons not reconciled to their situation. Their dissatisfaction can become so disruptive as to impair economic growth. Under the circumstances, a pre-emptive strategy to accommodate their ethnocentric aspirations can enhance a society's economic prospects. Attenuated sovereignty is the answer. Economic growth and attenuated sovereignty are relevant to each other, but not in the sense that a hostile critic would suggest.

Objection \#4. Social changes made possible by technological progress are already well on their way to fulfilling attenuated sovereignty's promise of lessened inter-ethnic tensions. To meddle with this process by instituting attenuated sovereignty would accent inter-ethnic differences and thereby exert a dangerously retrograde influence. Technology's most socially transformative fruits, i.e., the ease and the speed of both travel and communications, spur the growth of a trans-ethnic perspective. Most developed among the young and the better educated, it is less about cultural homogenization, though much of that does occur, than about continued ethnic diversity tempered by the decline of inter-ethnically abrasive attitudes and behaviors. Reciprocal acceptance and even appreciation of the ethnic other are becoming a universal norm. Attenuated sovereignty would be a giant step backward.

This objection is only half right and, therefore, woefully wrong. Modern technology's influences are not unidirectional. Rapid, inexpensive travel and even quicker, cheaper communications not only allow people to draw together, but also provide them the means to remain apart. German-born Turks living $\mathrm{n}$ Berlin have the option of regular, economical air travel to and from their forefathers' homeland in Anatolia. Their journeys "home" may either move them to feel more German or empower them to preserve their ethnic insularity in Germany. Intra-ethnic differences once again take on critical importance. Modern modes of communication are similarly open-ended with respect to social consequences. The Internet and cell phones help to involve Uighur's with the broader Chinese population, but these same technologies also prompt Uighurs everywhere in China to feel painfully apart when they learn, almost contemporaneously with the event, of the insult or rape of a Uighur migrant worker outside their ancestral Xinjiang. Before the advent of nearly instantaneous commu- nications, inter-ethnic insults and injuries were isolated, local matters not subject to such widespread publicity. Never again will that be the case.

The use of this or that modern technology does not determine whether a person will be more or less ethnocentric. Individual preferences representative of intra-ethnic differences trump technology. For the more ethnocentrically inclined, attenuated sovereignty remains a reasonable proposal.

Objection \#5. Attenuated sovereignty should be rejected because of its antidemocratic biases. Its stress on ethnicity and its allegiance to an awkward notion of group rights betray scorn for the democratic axiom of "one person, one vote," the fundamental principle of good governance. An ethnic minority person who experiences the frustration of being marginalized in a democratic election may look forward to the next election when he might be in the majority, albeit not one ethnically defined. Diversity of all kinds-ethnic, ideological, religious, linguistic, etc.-enhances democratic self-government. The greater the diversity, the better the chance that election outcomes will hinge upon shifting electoral alliances. No one will feel confident of always being in the majority; everyone will have an incentive to act moderately lest he later find himself in the minority and subjected to a vindictive majority. Democracy, not attenuated sovereignty, offers the best hope for ethnic minorities.

The voting public does not corroborate this jubilant view of modern elections. Particularly in the longer established so-called democracies, voters experience elections as confidence tricks to keep them calm and obedient to unelected bureaucrats who, in the name of elected politicians, execute government's workaday sovereign functions. Voters reject the argument vaunting "diversity of all kinds" as a boon for democracy. Although diversity-induced "shifting electoral alliances" are real enough, they get manipulated by politicians creating new alliances and subverting older ones to ratchet up-never to ratchet down - the powers government. The consistent losers in this process are the voters who experience less and less latitude, whether they act individually or in voluntary concert with others, to conduct their own affairs without coming under the purview of politicians and officious bureaucrats. This is not democratic in either the historical or etymological senses the word. The Greeks, who invented democracy, insisted that the ethnic unity of the people, the demos, was its indispensable precondition. Within such a 
population, most matters are decided below the level of politics. The nonpolitical decisions are largely consensual; they get made pursuant to social norms and by means of interpersonal cajolery. Political decisions, which are the formal decisions of the demos as a whole, are few and far between. For the losing partisans in these democratically settled determinations, their loss is like that of the losing side in a family quarrel, regrettable and perhaps hurtful, but not destructive of social bonds.

Only in such an environment is democratic selfgovernment possible. Political systems with claims to popular legitimacy should be divided into two categories, viz., the democratic and the merely electoral. Modern mass "democracies" clearly fall into the second category. Attenuated-sovereignty regimes would trend toward democracy, though they probably would not be without some features of merely electoral systems.

Objection \#6. Time spent discussing attenuated sovereignty, let alone working to implement it, is an utter waste of time. No conventionally sovereign government will ever permit an ethnic minority to establish attenuated sovereignty on any portion of its territory.

The politically relevant generalization least likely to meet with exceptions is that politicians act to further their own perceived interests (usually while professing their altruistic disinterestedness). This being the case, attenuated sovereignty has good prospects. There are many places where politicians who can decide its fate would benefit from "washing their hands of" this or that ethnic minority people and allowing the willing among them to go their own way with attenuated sovereignty. Russian politicians could become zealous advocates of attenuated sovereignty. If their country's demographic trends do not change, ethnic Russians will become a minority. The prophylactic introduction of attenuated sovereignty for selected minorities would increase the odds that ethnic Russians will continue to control Russia. With somewhat less urgency, a similar logic should appeal to Chinese politicians who could benefit both domestically and internationally by allowing attenuated sovereignty for Uighurs and Tibetans in the more sparsely populated, less economically productive parts of Xinjiang and Tibet. Much of southern Asia, including the Middle East, offers analogous opportunities for ambitious politicians. In Afghanistan, attenuated sovereignty for each of half a dozen or so minorities might enable the Afghan central government, not to preserve its authority, but to establish it in the first place.

Africa boasts more situations suitable to attenuated sovereignty than does any other continent. Burundian and Rwandan politicians might seize upon attenuated sovereignty as a palliative for their respective countries' chronic tensions between Hutus and Tutsis. In South Africa, any black-majority government (and South Africa will never again have another kind) could employ attenuated sovereignty to convert even the most bitter and backwardlooking Afrikaners into its supporters.

The South African situation has a parallel in South America where Bolivia's indigenous President Evo Morales could use attenuated sovereignty to mollify the population of European descent in the country's eastern lowlands. Several other South American states, notably Guyana and Trinidad and Tobago, also could institute attenuated sovereignty to reduce inter-ethnic tensions.

Attenuated sovereignty could prove enormously appealing to politicians in the developed countries on both sides of the North Atlantic. Compounding inter-ethnic tensions in this region, a severe cognitive dissonance afflicts the prevalent understanding of individualism's social character. Undisciplined thought and conflicting political initiatives proliferate as politicians and their supporters flit back and forth between promoting individual or group rights. The key to promoting both without sacrificing either lies in the recognition of the territorial dimension of human life. Attenuated sovereignty, which is rooted in this recognition, stands forth as an eminently practical course of action.

\section{The Challenges Ahead}

The conventionally sovereign state's best years are behind it. Its days are numbered. Although some forms of political organization will probably still be called "sovereign" well into the future, they will likely be seen as strangely denatured mutations of the historical sovereign state. The crowning achievement of post-medieval statecraft, the sovereign state is now at bay. It lacks the resilience to withstand the onslaught of challenges rising to confront it.

Challenges widely recognized by scholars and journalists come from various international organizations whose influences, in a familiar phrase, "chip away at" the sovereignty of existing states. Noteworthy organizations having this effect include the United Nations, the World Bank, the International Monetary Fund, and the World Trade Organization, as well as such regional associations as the European Union and the several states grouped together by the North American Free Trade Agreement (NAFTA). The International Criminal Court, a relative newcomer, is poised to become a serious foe of sovereignty. More loosely structured groupings threaten to be no less effective on that account. The global bond market, which can coerce even the most powerful sovereign states, and various narrowly focused "communities" formed in cyberspace fall into this category. 
Also imperiling the sovereign state are "non-state actors," to use a phrase popular in academic circles, and innovations in legal thought having global implications. At present, the most significant non-state actors are various multinational business corporations, certain terrorist groups, and some organized religions. The most important legal innovations detrimental to sovereignty are the fledgling doctrine of "universal criminal jurisdiction" and the much longer established, though still open-ended in its particulars, notion of universally valid human rights.

By far the most dangerous assault on sovereignty is emerging in the changing attitudes of the citizen/subject populations of existing sovereign states. The attitudes of "the people" toward their respective governments transcend ambivalence and are already enmeshed in destabilizing contradictions. While people feel an ever more insistent sense of entitlement to the benefits provided by their governments, and while they often demand even more governmentguaranteed security, they also experience a growing alienation from their governments. More and more, a citizen's allegiance to his government is qualified by extreme reluctance and aversion. Conditions are ripe for abrupt political changes.

One such change could be in the form of attenuated sovereignty. In some situations, for some people, attenuated sovereignty would offer them the opportunity to pledge unemibittered allegiance to a sovereign government, albeit not a conventionally sovereign one. The desire to experience some sort of social solidarity is an enduring aspect of the human condition. Satisfying this desire, however imperfectly, is important for most adults and essential to the socialization of children who learn, from innumerable signals offered them by their parents and others, that "people like us" act in such and such ways. Inevitably, multiethnic societies give mixed and conflicting socializing signals. People of all ages commonly respond by seeking a sociability in which such internal frictions are reduced or eliminated. Renewed or altogether new sociabilities may take root in the fertile soils of ethnicity, ideology, or religion, Of these, ethnicity may not have the best reputation, but it does have the longest track record and can more comprehensively enlist a range of human energies - reason, nostalgia, unreasoned mutual affection, hope, etc.- - than can either ideology or religion.

Attenuated sovereignty is ideally suited to minorities within minorities. It is not for everyone. It is not the wave of the future, there being no such single wave. Possibly under a different name, however, attenuated sovereignty or something closely akin to it will become an accepted way in which people can organize themselves politically. The numbers of people who will so benefit-both those who would align themselves with an attenuated-sovereignty government and those who would be relieved by the withdrawal of such ethnocentric persons from a wider polity-are so great that this is a likely development. Uniquely informed by an innovative yet historically precedented adaptation to the imperative that government must govern people on land where they live, attenuated sovereignty affords the only realistic path to reconciling ethnic solidarity with individual choice in multiethnic societies.

Chris Woltermann received his $\mathrm{Ph} . \mathrm{D}$. in political science from Purdue University. He has published in such journals as Telos, Humanitas, and The Canadian Review of Studies in Nationalism. 